\section{Varianz, gepoolte}

R.-D. Hilgers ${ }^{1}$, N. Heussen ${ }^{1}$ und S. Stanzel ${ }^{2}$

${ }^{1}$ Institut für Medizinische Statistik, Universitätsklinikum der RWTH Aachen, Aachen, Deutschland

${ }^{2}$ DKFZ Heidelberg, Heidelberg, Deutschland

Englischer Begriff pooled variance

Definition Die gepoolte Varianz misst die gemeinsame - Variabilität innerhalb von 2 oder mehr Stichproben (s. > Stichprobe), deren Messergebnisse (s. \ Messergebnis) miteinander kombiniert werden sollen.
Beschreibung Im allgemeinen Fall von $\mathrm{k}$ Stichproben mit Stichprobenumfängen $\mathrm{n}_{1}, \ldots, \mathrm{n}_{\mathrm{k}}$ ergibt sich die gepoolte Varianz als eine Art „fallzahlgewichtete Mittelung“der Stichprobenvarianzen $\mathrm{s}_{1}^{2}, \ldots, \mathrm{s}_{\mathrm{k}}^{2}(\triangleright$ Varianz) der $\mathrm{k}$ einzelnen Stichproben:

$$
\mathrm{S}_{\mathrm{p}}^{2}=\frac{(\mathrm{n}-1) \times \mathrm{s}_{\mathrm{x}}^{2}+(\mathrm{m}-1) \times \mathrm{s}_{\mathrm{y}}^{2}}{\mathrm{n}+\mathrm{m}-2}
$$

\section{Literatur}

Glantz SA (1992) Primer of biostatistics, 3. Aufl. McGraw-Hill, New York 